\title{
Against a Nomic Virtue Epistemology
}

\author{
CONTRA UNA EPISTEMOLOGĹA DE VIRTUDES NÓMICA
}

Modesto Gómez-Alonso

\begin{abstract}
In Judgment and Agency, Ernest Sosa argues for a particular methodology-what he calls 'metaphysical analysis' - whose aim is to provide a specific sort of explanation of knowledge - a metaphysical explanation- As I read it, this revolutionary step points to the bulk of the ontological dispositional web that necessarily sustains a virtue epistemology, contributes to a proper understanding of accidentality in epistemology, and breaks the hold of Humean contingency. I will argue that Sosa's account of the constitution of knowledge is not only able to rule out apparent counterexamples to a robust virtue epistemology, as well as to combine rational integration and knowledge explanation, but that also breaks the Pyrrhonian (and internalist) impasse. I will also argue that a principled distinction between cases of knowledge and cases of mimicking is unavailable to anti-luck virtue epistemologists, so that they face a dilemma between their theory collapsing into a robust virtue epistemology or its collapsing into a form of nomic virtue epistemology. What binds anti-luck virtue epistemologies and nomic theories together is a common problem in binding, one that is absent from a theory, such as Sosa's theory, that locates knowledge in the domain of higher-order competences and rational guidance.
\end{abstract}

KEYWORDS: Anti-luck virtue epistemology; dispositional directedness; Humean contingency; mimics; nomic necessities.

\section{RESUMEN}

En Judgment and Agency, Ernest Sosa defiende una metodología específica -a la que denomina 'análisis metafísico' - cuya función es la de proporcionar una explicación particular del conocimiento - una explicación metafísica- Se trata de un procedimiento significativo, que apunta a la red disposicional que necesariamente sostiene a la epistemología de virtudes, contribuye a la comprensión adecuada de la accidentalidad en epistemología, y rompe el dominio de la contingencia humeana. En este artículo argumento que la explicación que Sosa proporciona de la constitución del conocimiento, además de evitar aparentes contraejemplos para una epistemología de virtudes robusta y de combinar la explicación del conocimiento y la integración ra- 
cional, es una herramienta fundamental para contrarrestar las intuiciones pirrónicas (e internistas). También argumento que la 'epistemología de virtudes anti-suerte' es incapaz de establecer una diferencia razonada entre casos de conocimiento y casos de acierto accidental debidos a la intervención de bloqueadores epistémicos (mimics), de forma que dicha teoría solo puede optar entre una epistemología de virtudes robusta y una epistemología de virtudes nómica. Es el problema de la combinación adecuada de los factores que contribuyen al conocimiento aquello que vincula epistemología de virtudes nómica y epistemología de virtudes anti-suerte. Dicho problema no existe en teorías como la de Sosa, teorías para las que el conocimiento es explicable en función de competencias de segundo orden y guía racional apropiada.

PALABRAS CLAVE: Bloqueadores epistémicos; contingencia humeana; direccionalidad disposicional; epistemología de virtudes anti-suerte; necesidades nómicas.

Nomic theorists view laws of nature as relations of necessity that connect the dispositional nature and the behaviour of objects, that is, as constituting nomic necessities that are metaphysically contingent, so that in other possible worlds under the jurisdiction of different laws a target intrinsic disposition would yield different results from those obtaining in the actual world. It is the apparent fact that nomic theories seem to rule out accidentality and to provide a principled distinction between genuine manifestations of dispositions and mimics by keeping the laws of nature fixed that plausibly explains their significance, as well as their pull on some developing varieties of virtue epistemology.

Anti-luck virtue epistemologists are not prima facie committed to a nomic theory. However, their account faces such a pressure from mimics that it might easily develop nomic responses to that challenge to counter internal disintegration. More importantly, what binds anti-luck virtue epistemologies and nomic theories together is a common problem in binding: a common ground of assumptions that make proper combinations, either in epistemology or in ontology, impossible; a particular way of conceiving extrinsic factors for the constitution of knowledge such that it contains an unequivocal rejection of internal relations and intrinsic competences. By arguing against a nomic virtue epistemology I will focus as much on the Humean contingency that permeates both views as I will do on the categorical nomic profile that an anti-luck virtue epistemology would take when cornered.

The main objective of this paper is, however, positive. It seems to me that the full significance (and the ontological depth) of Sosa's comprehensive view can be better appreciated against a background of alternative models that, while 
preventing rational integration and knowledge explanation, seem to be imperative. This paper aims at tracing connections, and thus, at underlining the systematic character and broad scope of Sosa's philosophy.

Here is the plan. After presenting the notion of 'metaphysical analysis' and contrasting it with some versions of Humean contingency in epistemology (section 1), I will consider, in section 2, a prominent counterexample to robust virtue epistemology that seems to provide an excellent reason for introducing a new variety of epistemic luck incompatible with knowledge (environmental luck) and thus for supporting an anti-luck virtue epistemology. I will argue that the latter conclusion is premature, if only because cognitive dispositions, being a relevant part of anti-luck virtue epistemologies (the part that makes of them members of the general class 'virtue epistemology'), invite questions about their nature and the role they play on this model to acquire knowledge. Dispositions open the path beyond conceptual analysis for anti-luck virtue epistemologists. What the latter could say on this issue is crucial for the viability of their position. In section 3, I will argue that anti-luck virtue epistemologists are dialectically forced to conceive cognitive dispositions that under the appropriate circumstances result in knowledge either as extrinsic dispositions or as partially intrinsic dispositions. The trouble is that, either way, a principled (ontological) distinction between cases of knowledge and cases of mimicking is prevented. The anti-luck virtue epistemologist thus faces a dilemma between her theory collapsing into a robust virtue epistemology or its collapsing into a virulent form of nomic virtue epistemology. Although the ontological commitments of an anti-luck virtue epistemology have not, as far as I am aware, been made explicit, the proposed reconstruction is the only one that, to my mind, makes sense of the theory. Finally, in section 4, I will consider Sosa's way of dealing with the counterexample of section 2 . The conclusion is that if the measure of success for a theory is its internal coherence, its ability to reconcile our intuitions with the metaphysical picture that it provides, and its capacity to resolve pressing philosophical puzzles, Sosa's epistemology fares extremely well in all those respects. This article thus aims at contributing to the understanding of accidentality in epistemology, by pointing to what appears to me as the bulk of the ontological iceberg (or of the dispositional web) that necessarily sustains a virtue epistemology, and by applying to epistemology the middle view 'between internalism and externalism' that as early as in 1993 Sosa successfully developed for concept-acquisition. ${ }^{1}$

${ }^{1}$ See Sosa $(1993,311-29)$. 


\section{TOWARDS METAPHYSICAL ANALYSIS}

It is common to understand epistemic justification in terms of internal rationality and of the agent's epistemic blamelessness. The problem of the new evil demon for reliabilist accounts of justification (Lehrer \& Cohen 1983, 191207) stems from the intuition that, since the beliefs of the demon's victim would be justified independently of her (unpropitious) emplacement, reliable beliefforming processes are not even necessary conditions for justification. It thus seems as if the intuition that justification is indicative of truth were swamped by the equally strong intuition that justification is connected to an exercise of rationality that, as such, is wholly isolated from external factors.

In his contribution to Epistemic Justification, Sosa addresses the new evil demon problem by differentiating subjective from objective justification in a manner that accommodates our intuitions (Bonjour \& Sosa 2003, 156-65). His point is that the concept of justification of special interest for epistemologists goes well beyond the blamelessness and subjective justification (justification in terms of the agent's conforming to her deep epistemic standards) enjoyed even by brainwashed agents and by agents raised within an epistemic community that inculcates prejudices through cultural assimilation. It is such truth-conductive justification, one that could only be explainable by appealing to reliable processes external to the contents of the believer's experience, what the internalist conception of justification fails to capture. ${ }^{2}$

Interestingly, Sosa manages to agree with the intuition that the demon's victim is epistemically justified while reinterpreting such justification in the much stronger sense of objective justification, and thus, while displaying a deep disanalogy between demon's victims and brainwashed agents.

Unlike the latter, the former acquire and sustain their beliefs through cognitive dispositions that are virtuous in the actual world, where a belief-forming process is virtuous (it is an operative cognitive virtue) only if it would produce a high ratio of true beliefs (a ratio that, of course, varies from domain to domain). Were the demon's victims located in more congenial surroundings, their beliefs would not

\footnotetext{
${ }^{2}$ Something analogous happens when, at the beginning of the Third Meditation, Descartes claims that even the cogito, in spite of reaching the highest possible standing according to the Meditator's deep epistemic standards, falls epistemically short. For Descartes, the epistemic status of beliefs depends on the agent's epistemic constitution. And such constitution is anything but internal to the subject's experience.

For a reading of Descartes' epistemological project as an early variety of virtue perspectivism, see (among many others) the chapter 7, "Human knowledge, animal and reflective", of Reflective Knowledge (Sosa 2009, 135-53).
} 
only be adroit (as they are), but accurate, and even apt. One could thus plausibly claim that, according to Sosa's earlier view, a hostile environment such as the demon's world prevents a cognitive disposition to be manifested as knowledge, ${ }^{3}$ and, correlatively, that the possession on the part of the agent of a cognitive disposition does not depend on the satisfaction of the conditions for its manifestation, conditions that might be blocked, inhibited or unavailable while the disposition is still there, in-waiting. ${ }^{4}$ One thing is to claim that a cognitive disposition is not operative. Quite another is to claim that, because inoperative, it does not exist. ${ }^{5}$

It thus seems as if a would-be virtue epistemologist who either dissociates the environment from its pairing with intellectual virtues for mutual manifestation or makes of it an extrinsic constituting part of the virtue would have to face the problem of how to accommodate within her view the concept of adroitness. Given the central role that adroitness plays within a virtue epistemology and its substantive contents, finding a solution to this problem seems far from easy.

The thing is that in Judgment and Agency Sosa advances a theory of competence (Sosa 2015, 95-106) that, while in keeping with his previous view, develops a broader and richer account of its core contents.

Sosa defines a complete competence (Sosa 2015, 26-7, 95-6) in terms of a triple-S profile (Seat/ Shape/Situation) such that a complete competence can be properly attributed to $S$ when, in certain combinations of shape and situation, her innermost (seat) competence is manifested in the success of her performance. This means that the possession of a complete competence is defined in terms of the reciprocal partnership of innermost competence (cognitive disposition), proper shape of the agent (paying full attention, sober, awake...), and right environmental factors. ${ }^{6}$

\footnotetext{
${ }^{3}$ This means that, though in the Demon World the subject's intellectual virtues might still be manifested in the alethic affirmations and judgments that they would yield, they would fail to be manifested in the correctness of those alethic affirmations and judgments.

${ }^{4}$ As the demon hypothesis makes clear, there are even logical placeholders for continuant inbibitors.

${ }^{5} \mathrm{On}$ this view, epistemic justification is thus external to the inner operations of the agent, while also independent of the instantiation of the environmental factors to which an intellectual virtue is directed. Justified beliefs come from dispositions intrinsically directed to the truth that, however, might be prevented to be manifested as apt, and even as accurate beliefs.

${ }^{6}$ The picture is somehow more complicated, since competences can be just reliable enough without being infallible. This means that even when all three $\mathrm{S}$ conditions are satisfied by a performance and the agent tries to attain the relevant objective, she might not do so. However, it is not clear to what extent this qualification can be rightly applied to cognitive competences highly independent of medium and situation, to paradigm cases of perception, or to epistemic performances (in general) where situation and shape are instrumental to explain failure. In any case, this further topic is tangential to the main argument.
} 
Notice, however, that the SSS profile only defines the conditions for the manifestation of the innermost competence, a competence that, because it is retained by the performer even while absent the opportunity for manifesting it, does have, as well as a categorical character, a dispositional one. A complete competence is not thus a particular kind of competence (among others), but a competence that is complete, to wit, the right manifestation of a competence (or competences) relative to the results and their mode of production of interest for the describer. ${ }^{7}$ This means that factors pertaining to the shape and situation of the agent such as the above mentioned might all be necessary, but not sufficient for getting knowledge. As Sosa makes perfectly clear by describing the "appropriate shape and situation" as the "background for archery shots" (Sosa 2015, 103), and, a fortiori, as the background for epistemic performances ${ }^{8}$, the cognitive disposition hosted by the agent will be the crucial factor for that. It is only putting the same point in other words to say that epistemic environments (environments relevant for the constitution of knowledge) are either blockers (if hostile) or (if fortunate) conditions for the manifestation of dispositions. They shall never take intrinsic dispositions away nor create them. ${ }^{9}$

\footnotetext{
${ }^{7}$ More on the perspectival nature of our taxonomies later.

${ }^{8}$ For reasons that I will later develop, I am not entirely satisfied with analysing manifestation in terms of an unmanifested disposition that combines with a set of background conditions. To my mind, this kind of talk is technically loose. However, it is successful as a gesture to the right sort of ontological picture, one where the distinction between the truthmakers of a cognitive disposition and those of its manifestations is front and centre.

${ }^{9}$ Dispositions are acquired and lost. They have causes. They form dispositional multi-level systems such that $S$ has a disposition $D_{1}$ to acquire a further disposition $D_{2}$ whose content is different from that of $D_{1}$, and so on and so forth. However, the directedness and selectiveness of a disposition is not its cause and cannot be explained by its cause. This means that the crucial factor to explain the success of a shot is the skill of the archer, and not how the skill was acquired. Etiological questions have become prominent in some (character) versions of virtue epistemology, with the subsequent confusion between the competences that constitute knowledge and the (non-constitutive) factors (which include ethical virtues) that are helpful to acquire and exercise those competences (cf. Sosa 2015, 41). The latter are not manifested in the result because they do not belong to the content and directedness of the cognitive disposition. The relevant point is, however, that reductive analyses of dispositions in terms of associated counterfactual conditionals that include a situational factor are unsuccessful, as C.B. Martin so forcefully demonstrated (Martin 2008, 12-23). By providing an analysis of the conditions for the manifestation of a disposition, the Simple Counterfactual Analysis takes for granted the disposition in question, so that it is unable to "reduce" it. As well as their environmental partners, dispositions have a life on their own.
} 
It would be quite misleading to describe Sosa's latest approach in terms of a "ontological turn", if only because, since his main concern has always been that of explaining the nature of knowledge, he has never been affected by or attracted to 'linguisticism in epistemology'. However, it seems also true that a particular methodology — what Sosa calls metaphysical analysis — whose aim is to provide a special sort of explanation of knowledge — a "metaphysical explanation" (Sosa 2015, 8) - has increasingly come to be at the center of his project. Sosa's ontological turn should not thus be considered as a philosophical shift, but as an expansion in depth of his view.

As I read it, one important aspect of metaphysical explanations is that they are reducible neither to explanations in terms of the conjunction of independent factors - the kind of result characteristic of what Sosa calls "factorizing analysis" (Sosa 2015, 16)—nor to causal relations where the relata are systematically but contingently connected. This means that the kind of dispositional analysis of knowledge provided by Sosa is such that, though it would be contingent that the dispositional partners from which knowledge comes exist and combine at all, it would not be contingent that such combination results in knowledge (as it would not be contingent that, given their respective dispositions, sugar dissolves in water, however contingent is the existence of sugar and water). If an internal relation is defined as founded on its relata in such a way that, as John Heil puts it, "if you have the relata, you thereby have the relation" (Heil 2012, 94), then a metaphysical analysis is the sort of procedure that makes internal relations explicit. Dispositionalities are paradigm 'objects' for such analysis.

Humean contingency permeates contemporary epistemologies, even if they are lucky enough to escape the impact of 'linguisticism'. It is expressed in the view that dispositions are causal relations connecting two logically independent events (belief and success). It informs nomic theories of dispositions, those according to which dispositions are partly conferred by the extant (and contingent) laws of nature..$^{10}$ It is curiously present, or so it seems, at the core itself of some varieties of virtue epistemology as the view that knowledge is a target that dispositional partners cannot get on their own, so that the unbridgeable gap between cognitive achievement and knowledge is always filled (if at all) by the grace of nature, that is, by a fortunate environment that is never able to properly combine with the corresponding virtue (where a 'proper combination' is one founded on the nature of the relata). Anti-

\footnotetext{
${ }^{10}$ For a view of laws of nature as dyadic relations of necessity that hold between (first-order) universals and that are themselves contingent states of affairs, see (Armstrong 1983, 158-71).
} 
luck conditions for knowledge thus seem contingent conditions for knowledge. As such, they are not capturable by metaphysical analysis.

Let us distinguish two senses of 'capturable'. It seems obvious that the richness of a dispositional base cannot be fully apprehended by a limited number of manifestations, and that, as Sosa is keen to underline (Sosa 2015, 26), even the right conditions for manifestation are not fully expressed in verbal formulas. This does not preclude, however, an analysis of the structure of knowledge, that is, an analysis of its ultimate sources, of their required ontological status, and of the way they have to stand to each other for constituting knowledge.

By contrast, anti-luck virtue epistemologies are prima facie committed to the view that the structure of knowledge is inapprehensible for the bare reason that there is no complete structure of which knowledge would be the tip to apprehend. Anti-luck virtue epistemologists are undeniably in the business of providing necessary and sufficient conditions for knowledge. However, the modally propitious environment that they consider as one of the crucial factors for explaining knowledge seems not to be itself a part of any structure, and thus, not a part of the structure that for a robust virtue epistemologist would constitute knowledge. The point is that, according to anti-luck virtue epistemology, skill and propitious environment are not for each other, that their relation is such that it is not built into the for-ness of the dispositional partners. Neither the agent's cognitive dispositions nor the environment are thus ready for knowledge. To my mind, this would mean that for anti-luck virtue epistemologists knowledge is groundless in the sense that it is not grounded on the reciprocity and mutual directedness of its bases. Because it would not be founded on the nature of the relata, knowledge would just be something that, under the right circumstances, happens. A brute fact, in short. ${ }^{11}$

${ }^{11}$ Objection: "Anti-luck virtue epistemologists claim that they are providing sufficient conditions for knowledge. If so, they would also be perfectly justified to claim that, since knowledge necessarily results from those conditions, knowledge is a relation founded on its relata (if you have the relata, you thereby have the relation). Another way to put this point is by saying that, though detached, both ability and propitious environment are manifested in the very fact that one knows. Anti-luck virtue epistemologists thus accept the same degree of contingency as robust virtue epistemologists do. No more. No less."

Reply: Even if anti-luck virtue epistemologists were right in claiming that, according to their view, the propitious environment and the relevant ability might well be manifested in knowledge, they would be providing a mereological account of knowledge. Since knowledge is necessarily connected with those conditions, since this connection must be explained somehow, and since those constituents, conceived as atomic or detached parts, cannot explain the connection, 
While it seems that for anti-luck virtue epistemologists knowledge comes from external relations that are, as such, contingent, the object of metaphysical analysis is a combination such that, in virtue of the intrinsic correlativeness and directedness of their relata, necessarily results in knowledge. Metaphysical analysis has a limited place, if any, in any variety of anti-luck virtue epistemology. Which means that the (ontological) question as to what knowledge is tends among anti-luck virtue epistemologists to collapse into the (conceptual and epistemic) question about the rules that govern the use of cognitive predicates, that is, about the conditions that have to be met for the application of 'knowledge', to a subject, to be justified. These properties may not be the ones that determine the nature of knowledge. Contrary to metaphysical analysis, conceptual analysis neither aims at providing nor is able to provide on its own an ontological explanation (an explanation without remainder) of why knowledge obtains. Metaphysical analysis is thus distinctive of a bottom-up epistemology. The route from talk of knowledge to the truthmakers for that talk is not conceptual.

\section{A TARGET TOO FAR}

Duncan Pritchard has vigorously advanced anti-luck virtue epistemology in a series of publications. ${ }^{12}$ As he aptly notes, what is essential for this theory is that it is a dual-condition view, one that incorporates as conditions for knowledge the ability condition stressed by robust virtue epistemologists and the anti-luck condition characteristic of safety-based epistemologies, and that, crucially, it incorporates them in such a way that "it accords each condition equal weight" as "they are each answering to a fundamental intuition about knowledge" (Pritchard 2010, 54). The

anti-luck virtue epistemologists would see that connection as 'magical'. What is required is an essentialist explanation of how knowledge involves those constituents. Anti-luck virtue epistemologists fail thus to capture an internal relation, one which is essential to its relata. The thing is that, deprived of such mutual disposition to combine, those factors are necessary for knowledge in the much restricted sense of Humean necessity: as regularly and systematically providing knowledge. It is a mere accident that a propitious and non-correlative-with-theability environment would result in knowledge when added to the ability: there is nothing there to explain why this necessarily happens (even if as now, and for the sake of the argument, one takes for granted that the addition of a safe emplacement to apt beliefs yields knowledge). In such a case, there would be no rationale for the result to obtain, and thus, no genuine explanation of knowledge. If you do not have the relata as relata (as potentially fitting each other), you only have an external relation - one that is not grounded on the relata at all-.

${ }^{12}$ See among others Pritchard (2009, 72-85), Pritchard (2010, 48-65), Pritchard (2012, 247-79). 
crux is thus that the intuitions that underlie those conditions cannot (as often happens) be run together, or, in other words, that they cannot be reduced to each other as if they were the two sides of a simple intuition. Knowledge is incompatible with most (but not all) varieties of luck. For many virtue epistemologists, the ability condition is enough to rule out all varieties of luck incompatible with knowledge. Pritchard's alternative view is motivated by what he sees as the failure of the ability condition to accomplish this purpose on its own, without the addition of a safety clause. $^{13}$

It is crucial for Pritchard's argument to clearly delineate cases of cognitive achievement without knowledge. ${ }^{14}$ His celebrated analysis of the case of Barney (Pritchard 2010, 35-40), who acquires a true belief that there is a barn in front of him through his cognitive abilities, while, unbeknownst to him, all the barns in the area but the one that is the target of his belief are 'barn-façades', provides such example. It seems intuitively correct to claim that Barney lacks knowledge. It also seems intuitive to claim that a reliable cognitive competence (visual perception) is manifested in the success of his belief. Barney's lack of knowledge thus has to be explained by a factor extrinsic to the agent's ability: by the fact that his beliefs are, relative to the circumstances, unsafe. The ability condition is thus unable to rule out what Pritchard calls environmental luck (Pritchard 2010, 50-1), the kind of luck that, incompatible with knowledge, is so conspicuous in the case of Barney.

Robust virtue epistemologists, when confronted with this formidable challenge, may opt for digging in their heels and for 'biting the bullet', by refusing to concede that Barney lacks knowledge. This move strikes to me, however, as pretty desperate. They might, alternatively, opt for conceding that Barney lacks knowledge, while explaining this by appealing to the agent's abilities, for instance, to the distinction between coarse-grained and fine-grained abilities. On this view, Barney lacks knowledge because his success does not manifest the ability to distinguish real barns from fake ones that would be required for achieving knowledge.

13 And the same goes for the safety condition when taken alone. It also fails to provide knowledge when the ability condition is not added to it, as Sosa argues when considering the case of beliefs about necessary truths that, though automatically safe, do acquire the status of knowledge only if properly based on a reliable cognitive competence (Sosa 2011, 85).

${ }^{14}$ And, conversely, to find cases of knowledge without cognitive achievement. However, I will skip this part of the overall argument against robust virtue epistemology because, in addition to being much more controversial than fake-barn scenarios, it is tangential to the main point of the following discussion. 
Maybe a view in very roughly this direction is, on further reflection, correct. However, this particular version does not seem too promising. On the one hand, it is far from clear what would be the distinction in terms of first-order abilities between Barney and his counterpart in a safe environment. Granted that perception and recognitional powers work in tandem, Barney still is as successful in identifying that particular barn as a barn as his counterpart would be. Barney could, of course, be charged with epistemic negligence, but this strategy, apart from raising epistemic standards too high (thus playing into the hands of the sceptic), would entail that his counterpart is equally negligent while getting knowledge. More importantly, this move does not apply to cognitive powers, such as rational intuition, whose correct operation is (at least to a high degree) independent of the epistemic quality of medium and environment. It is easy to see, for example, how a randomizing demon might be careless enough to allow his victim to form apt beliefs by using rational intuition while, due to the operating demon, those beliefs would easily be false. ${ }^{15}$ In such a case, that parallels that of Barney, the intuition that the victim's demon lacks knowledge stands firm, while explanations in terms of fine-grained abilities seem wholly unmotivated. ${ }^{16}$ Since the right explanation of knowledge should be general and unified, the present version of this general move seems to fall short of the challenge. The required level of generality, as well as the bleak prospects of composite first-order abilities, also seem to indicate that if there is a right place to look for a suitable candidate to explain knowledge (and the lack of it) by factors intrinsic to the agent's abilities, the domain of higher-order competences is it.

It is clear that anti-luck virtue epistemologies add an independent safety condition for knowledge. It is far from clear, however, how their defenders translate intuitions into epistemic theories, more specifically, how they combine the ability condition with the safety condition in such a way that knowledge would thus be explained.

One (attractive) way of reading their proposal would be as viewing statements attributing knowledge to $S$ as linked to a complete set of conditional statements,

\footnotetext{
${ }^{15}$ The randomizing demon, that Schaffer considers as one of the main predecessors of his debasing demon (Schaffer 2010, 231 n. 4), made his appearance in the case of Lucky Strikes, that Sosa discusses in the section 6.6. (a section that, pre-dating anti-luck virtue theories, is curiously and premonitorily entitled "Lucky Knowledge?") of Epistemic Justification. See Bonjour \& Sosa $(2003,115)$.

${ }^{16}$ If only because simple necessary truths are apprehended solely on the base of understanding them, without appeal to any other faculty or belief. This is a lesson from Descartes.
} 
where the set is defined by modal proximity. On this view, $S$ would know that $p$ at the target-occasion $O_{1}$, if, within a modal area $A$, all the beliefs ${ }^{17}$ acquired by $S$ about the relevant class of objects by using the same cognitive competence $C$ would be apt. ${ }^{18}$

Notice that this analysis fits well with our intuitions regarding the epistemic distinction between Barney and his counterpart within a safe location. Unlike the former, whose beliefs would be mostly inapt (because they would be mostly false), all the relevant beliefs of the latter would be apt. Notice too that cognitive abilities are neatly incorporated into this view, so that Pritchard seems perfectly justified in considering his theory as a modest virtue epistemology. However, on further reflection, this reading is beset by problems.

The first trouble comes from the fact that on this view a particular area seems to be defined as modally safe in terms of a collection of apt performances, so that the safety condition collapses into an ability condition such that, for a finite number of cases, would not yield divergent results. It thus seems far from clear how an anti-luck virtue epistemology could accord each condition equal weight when the safety condition would seem nothing else that a sum of apt beliefs. ${ }^{19}$

It is also intriguing to notice how, according to this interpretation, the very same performance gains or fails to gain knowledge for the agent depending on the truth-value of counterfactuals. Consider a single apt performance in itself. Were the counterfactuals true, that performance would by itself be enough to get knowledge. By contrast, the very same performance would never by itself be enough to get knowledge if the counterfactuals were false. This suggests an absurd picture: it is as if the right counterfactuals would modify the content of the ability, by loading it with a directedness to knowledge of which the ability is intrinsically deprived. The point is that, the target-ability being invariant, neither a single performance episode nor a collection of similar performances are able to reach out beyond the intrinsic limits of that ability. The target-abilities are paired to modally thin situations for their mutual manifestation. As such, a modally thick situation is

\footnotetext{
${ }^{17}$ Or 'most of them', if one opts for a less strict conception of safety than the one endorsed by Pritchard. The following discussion is neutral to this further (and interesting) topic.

${ }_{18}$ According to the standard use, a belief is apt when a cognitive competence hosted by the performer is manifested in its accuracy (success).

${ }^{19}$ This is fully compatible, however, with claiming that, even so, a modest virtue epistemology goes well beyond standard versions of virtue epistemology. My point only concerns the consequences of this reading for Pritchard's 'equality of weight'.
} 
always, whether one considers the performance alone or as relative to a collection of counterfactuals, beyond them.

Knowledge is thus irreducible to conditionals involving apt beliefs. A reductive conditional analysis fails to capture the core of the view proposed by anti-luck virtue epistemologists. A view that could be expressed by saying that, though it is not the environment (whether safe or not) what makes of $S$ 's belief an apt belief, it is the safe environment what makes of it knowledge. Knowledge exceeds aptness.

What would be then the role of cognitive abilities for explaining knowledge? There is a ready-made answer. Beliefs that are accurate because competent are not lucky as beliefs whose accuracy is due to an extrinsic factor (a mimic) are. Abilities thus prevent a certain sort of luck incompatible with knowledge, and in so doing, they select the right candidates for knowledge. Notice, however, that on this revised reading the safety condition is an independent condition that is not fulfilled by apt counterfactuals, so that the relevant factor for knowledge is a safe environment such that the target of knowledge is always (where 'always' should be interpreted modally) out of reach of cognitive abilities alone. It is now when the distinction between the factor that explains why a belief would be apt (the proper exercise of a competence) and the factor that explains why a belief would not easily be inapt (the safe environment) gains importance. When the set of counterfactuals is considered, the right picture is that of a collection of apt performances that are tied together by a safe environment. When our consideration is limited to the actual performance, the correct picture is that of an apt performance that is tied to knowledge by a safe environment. Knowledge is thus fully actual on any particular occasion. Talk about counterfactuals and possible worlds that make them true is nothing else that a useful form of representation. Provided with a cognitive disposition base that is fully actual on the occasion, with a manifestation that shares the same feature, and with an environment that is anything but virtual, anti-luck virtue epistemologies are thus not necessarily burdened by an excessive package of metaphysical commitments. The main point is, however, that the two conditions come together for knowledge without (in an ontological sense) combining together. Independence and equality are preserved, while knowledge, apparently, is fully explained.

The trouble for this view (coordination without combination) comes from mimics, that is to say, from those extrinsic factors that, incompatible with knowledge, make bogus competences appear as if they were genuine.

Before starting the discussion, let us be clear on one crucial point. Our present worry is not about the epistemological problem of how to discriminate between the bona 
fide manifestation of a competence and a mimic, nor about the sceptical challenge to the possibility for epistemic agents of detecting and ruling out mimics. Our worry concerns the ontological distinction between those cases in which the agent's successful performance is explained by her competence and those other cases in which, because the success is not attributable to the agent, it comes from chance. This distinction would stand fast even if the Pyrrhonian problematic were intractable. ${ }^{20}$ The problem is thus about the nature of knowledge, and not about if knowledge is humanly discernible. Our point will be that anti-luck virtue epistemologies threaten to undermine the ontological distinction, and thus, that, instead of explaining what knowledge is, they make a new contribution to mimic-ology.

When C.B. Martin introduced interferences and finks in the literature about dispositions (Martin 1994, 1-8), it was with the objective of providing counterexamples to the analysis of dispositions in terms of counterfactuals. Among the several cases of interferences that undermine the conditional analysis, mimics are cases in which either a disposition ascription is false even if its associated conditional is true (a diamond is not intrinsically disposed to turn into dust when lightly touched, even if a powerful spell would make it true that if the the diamond were lightly touched it would turn into dust) or, alternatively, cases in which, even if the disposition ascription happens to be true, that is not the reason that makes the associated conditional true (a wire can be live and ready for manifestation

${ }^{20}$ Radical sceptics do not reject the ontological distinction, but our capacity to know whether our beliefs come from competences or not, and thus, our cognitive ability to improve our epistemic standing beyond mere natural inclinations. For them, our condition is similar to that of "archers shooting at a target in the dark" ( $M$ viii, 325$)$, so that, though some (or many, or even all) of our evaluations are true, no one can properly claim that her evaluation is true. This also means that for the Pyrrhonians proper epistemic functions (of the type currently endorsed by reliabilists such as Goldman), although they were objectively right, would never be sufficient to constitute knowledge. Knowledge is located by the Pyrrhonians on the metalevel, so that even the man who enters into a dark room which, unbeknownst to him, only contains objects made of gold would grasp a golden object by luck. This is just the sort of example that anti-luck virtue epistemologists fail to consider. One that is instrumental to show why first-order competences together with safe environments are not enough to make of a success in such conditions something more than an accidental success (and not a case of knowledge), and that unambiguously points to the right direction of enquiry: the domain of higher-order performances. There are more varieties of luck in epistemology that anti-luck virtue epistemologists dream of.

For the long and deep involvement of Sosa with the Pyrrhonian conception of the structure of knowledge, see (among others) Sosa (1997, 229-49), and Sosa (2015, 215-32). 
while, because of the trumping effect of an electro-fink, that is not the right explanation for why the current is flowing).

Since cognitive competences are understood by virtue epistemologists in terms of dispositional powers, mimics have become, unsurprisingly, prominent in recent literature. Consider, for example, Sosa's case of a benign angel (Sosa 2015, 103), a case that falls under our first variety of mimics: those that operate by faking a competence that does not exist.

BENIGN ANGEL. An epistemic agent is not intrinsically disposed to get it right on her perceptual belief that $p$ when so believing. However, a benign angel casts a spell that makes his perceptual belief true, so that if the agent were to believe that $p$, his belief would be immediately true.

Consider now a variation of the previous case that falls under the second variety of mimics: those that operate by replacing a competence that, with the appropriate SSS profile, is ready for manifestation.

BENIGN ANGEL*. Situation and shape are such that, were the agent to form a perceptual belief that $p$ through competence, they would combine together as to render an apt belief. However, a benign angel interferes, so that, though the agent's belief is true, its truth is not due to her competence.

There are two important things to notice about the previous examples. First, mimics provide a causal explanation of the performance's success at the expense of making it accidental. A target is thus accidentally hit for all the cases in which that outcome does not manifest the competence of the agent. Second, cases of mimicking are compatible with the fact that the agent regularly succeeds in acquiring true beliefs, so that she might have a system of true beliefs as extensive as the describer stipulates while, because all of them would be accidentally true, deprived of knowledge. A spell is not less a spell because it makes all diamonds to turn into dust when lightly touched. A benign angel is not less a mimic because it interferes with all the beliefs of all the epistemic agents. No external influence, whether it is regular or episodic, confers dispositions.

The thing is that for anti-luck virtue epistemologists competences always fall short of the target of knowledge, and that, according to their view, it is an external influence (the safe environment) that fills the gap between apt beliefs and knowledge. This suggests that, since no competence explains a cognitive success higher than that of affirming correctly, hitting the target of knowledge is always an accidental fact, and that, on this view, the safe environment is nothing else than the causal factor that provides a causal explanation for that outcome, just as mimics do. 
It eludes me how the safe environment might be the anti-luck factor in the analysis of knowledge when the result is accidental, since it comes from no competence at all. It also eludes me how that accidental outcome could be called 'knowledge' when 'lucky knowledge' is a contradictory expression. The challenge for the anti-luck virtue epistemologists is thus that of providing us with good reasons to believe that the case of Barney's counterpart in a safe environment is not a case of mimicking. Why would a safe environment be different from a benign angel? Why would one confer knowledge while the other would be incompatible with it?

At this point, it might be tempting to think that, contrary to what happens in the case of standard mimics, a safe environment neither replaces a cognitive competence nor makes it appear as if the agent hosts a non-existent competence. After all, the safe environment, far from mimicking an ability, is a supplement to it, for the purpose of explaining knowledge.

However, and as a consequence of wrongly keeping first-order apt belief, instead of knowledge, fixed, this response ignores one crucial consideration. The contrast is not here between the outcome of a target-ability (visual perception) that is, by hypothesis, fully operative on the occasion and a mimic that would produce the same result, but between the outcome of an ability that is yet to be determined such that the apt belief would intuitively constitute knowledge and a mimic that would accidentally produce the same true belief. Curiously, the a priori rejection of such an ability to which anti-luck virtue epistemologists seem committed would be tantamount to the rejection of the ontological distinction, ${ }^{21}$ and thus, to the claim that there is no knowledge at all. Falling short of competence, knowledge just is an accidental fact causally explained by an external factor. In short, the result of a mimic. In short, anything except knowledge. On this view, first-order abilities prevent a certain sort of luck at the cost of making luck pervasive. ${ }^{22}$

${ }^{21}$ Again, the ontological distinction does not entail any commitment to the claim that cases of knowledge are (at least on some occasion) instantiated. The point is that there is a contrast between a situation such that knowledge would be achieved and cases of mimicking, a contrast that holds even if as a matter of fact there were no cases of knowledge. Knowledge and mimics are categories that stand or fall together. Each makes sense because the contrast between them makes sense. In this respect, anti-luck virtue epistemologists not only would be committed to claim that knowledge is impossible to acquire, but to the stronger claim that knowledge is unintelligible. This would result in an invitation to abandon, as well as epistemology, meta-epistemology.

22 The trick from which the disanalogy between safe environment and mimics comes lies in contrasting the first-order operative competence with the agent's emplacement. It is enough to notice that the modally thick environment should rightly be paired to the exercise of an 
It is also of no avail to appeal to the distinction between the intentional agents such as wizards, benign angels and the omnipotent God of the Cartesian lore that populate the literature on mimics, and a safe environment where no external agency is involved at all. Intentional imaginery is only employed for the purpose of making a more vivid and dramatic picture of the nature of mimics. For making the same point, it could easily be replaced by neutral extrinsic factors, such as the extant laws of nature (with no theistic underpinnings) and the dark rooms full of objects made of gold that come from the Pyrrhonian tradition. A mimic is an extrinsic factor (one that does not combine with the agent's competence) that provides an explanation of success such that the explanation entails accidentality, however the nature of that factor could be.

Finally, and because, though a sporadic success is always an accidental one, an accidental success is not necessarily an episodic one, Barney's counterpart is not less deprived of knowledge than Barney is, no matter how many of his relevant beliefs would be apt. On the one hand, his beliefs would fall short of knowledge even if all of them were apt. On the other hand, all his beliefs would (while aptly formed within such an environment) be true, but accidentally so. A mimic is not less a mimic because it interferes with an extensive set of beliefs, as well as a lucky shot is not less lucky because it is not a blind shot. A stable class of true beliefs does not make knowledge.

This brings us to the underlying mistake of anti-luck virtue epistemologists: that of taking for granted that, without further qualifications, Barney's counterpart really knows that there is a barn in front of him.

Consider the following case.

DARK ROOM. Goldie steps into a pitch dark room that, unbeknownst to her, only contains objects made of gold. Due to the the contents of the room, and to her motor and grasping skills, there is no chance for her but to hit upon gold. Despite all this, her success is in a relevant sense accidental. It was by a stroke of luck that Goldie hit upon gold.

It would be very tempting to think in the following terms. What this case suggests is that it is not enough for an environment to be safe that a particular area

ability that, by hypothesis, could not fall short of knowledge for appreciating that a detached environment always is a mimic. By rejecting that ability, anti-luck virtue epistemologists would commit themselves to the claim that knowledge is impossible. By rejecting that a safe environment is a mimic, the very notion of knowledge would collapse. 
happens to be safe. It is also required that the agent could not easily be situated within an unsafe area, or, in other words, that the situation could not easily be unsafe. In this sense, it is only when Goldie might easily step into a modally close room that contains objects made from different metals and alloys that she lacks knowledge. The suggestion is thus that of reading the safety clause as a super-strong safety, one that is met in cases where factors that would make the area unsafe are remote possibilities not liable to occur. Those possibilities would be too distant to count as relevant for knowledge.

This move could allow anti-luck virtue epistemologists to deal with cases such as DARK ROOM ${ }^{23}$ without abandoning their intuitions. The trouble is that those cases point to an opposite direction. It is not that Goldie lacks knowledge because she might too easily be wrongly situated, but because, no matter how strong the safety of the environment is, her high epistemic standing would not be due to the exercise of a competence. Her success as a knower would still be accidental, even if, unbeknownst to her, in and around her position there only were rooms that contain gold. ${ }^{24} \mathrm{As}$, in spite of the same behaviour, there is all the difference in the world between acting (systematically but accidentally) according to a rule and rulefollowing in virtue of dispositional constitutions, there is an analogous distinction between safely but accidentally collecting truths and achieving knowledgeable truths by competence. The point is thus that the environment, whether weakly or strongly safe, provides the causal explanation of a success that, falling short of competence, is accidental. The environment is not magically transmuted into

23 This family of cases include the example of Simone (Sosa 2015, 146-53), that of the randomizing demon that allows his victims to form an extensive class of apt beliefs in an environment that just happens to be safe while at any moment the demon could easily be operative, and that of Barney's forming the apt belief that a barn is in front of him within a safe environment while, unbeknownst to him, the town council has decided to raise many barn-façades, so that Barney could have easily been in an unsafe area.

${ }^{24}$ A quite different (but equally pressing) worry arises from the Pyrrhonian intuition that what explains that Goldie does not know is that she cannot properly claim that she has hit upon the truth. On this view, one that takes as primary for a proper account of knowledge the first-person perspective of the performer, neither a safe environment nor the manifestation of a competence that would be unavailable from the internal perspective of the agent would be sufficient to yield knowledge. Competent or not, the success would be accidental for the performer. Both Pyrrhonians and Classical Internalists take this argument as decisive to undermine any variety of externalism in epistemology, including any member of the family 'virtue epistemology'. It remains to see whether Sosa's virtue perspectivism has the appropriate resources to meet this challenge. More on this later. 
the factor that confer epistemic dispositions to the agent by adding stability to it. Universal mimics are still mimics.

Where does this leave us? We seem to be threatened by an impasse of sorts. Both robust virtue epistemologists and anti-luck virtue epistemologists face serious problems. The former theorists seem unable to explain Barney's lack of knowledge by appealing to factors intrinsic to his abilities. The latter ones fail at distinguishing between cases of knowledge and cases of mimicking, so that, paraphrasing Nietzsche, they banish competences out the front door only to rush to the back door to let accidentality in. The problem is that accidentality will come to remain, and that epistemologists would then have no other option but to leave. It seems thus clear that anti-luck virtue epistemologists have succumbed to a philosophical error alarmingly prominent: that of continuing to rely implicitly upon something, in this case a conception of knowledge such that the connection between competence and environment is so strong as to be considered as an internal relation, that they are explicitly repudiating in their positive view.

The solution is to find a competence that combines with a modally thick environment, one such that the overall situation is loaded into the conditions for the manifestation of the competence. A question remains. Could an anti-luck virtue epistemologist take the only remaining safe path while retaining the core of her theory?

\section{EXtrinsic and Partially Intrinsic Cognitive Dispositions}

Haunted by mimics, anti-luck virtue epistemologists would easily be tempted to explore two more avenues that, while according to a (yet to be determined) competence a main role in explaining knowledge, make of the situation (whether a narrow situation or one so extensive as to include nomological facts about the actual world) the crucial factor for that purpose. The point would be that, antiluck virtue epistemologists being unable to get rid of competences paired to modally thick environments for explaining knowledge, it is still open for them to explain those very abilities (or their pairing to a class of environments) in terms of extrinsic factors, so that virtues alone would never be able to confer the cognitive dispositions relevant for knowledge on their bearers. This strategy would yield a dual-condition view of sorts, one where, instead of an additional factor to competences, the safe environment is one of the factors that constitute them. It would also be instrumental for anti-luck virtue epistemologists in avoiding the pitfall of mimics. After all, if safe environments constitute competences, there is 
no prima facie plausible way to draw a contrast between the exercise of an ability and the environment seen as a mimic. On this model, it would be the right kind of situation that makes $S$ to be disposed to get knowledge by using her cognitive ability, or, alternatively, it would be an extrinsic factor that which rightly connects the competence and the situation. One could thus go externalist while firmly rooted in the agent's capacities.

Let us consider the first alternative, that of viewing the dispositions relevant for knowledge as extrinsic dispositions.

In the literature about powers and dispositions, an extrinsic disposition is, contrary to intrinsic dispositions that either supervene or are identical to the categorical properties of the object, ${ }^{25}$ one that an object acquires and loses without undergoing some intrinsic change. This means that an extrinsic disposition is not hosted by the object intrinsically, to wit, that it is one that is directed to a particularpartner for mutual manifestation in such a way that the factor that provides the disposition is the causal context. The tip of a screwdriver fits in this particular slotted screw head, so that, were it to be inserted in the slots, the process of losing the panels encasing the boiler would start. However, were the slots of the screw head changed, the screwdriver would lose its disposition to fit this particular screw head without suffering any change whatever. Externalism thus enters into the account of dispositions.

Analogously, one may claim that the bearer of an intrinsic cognitive disposition that, directed to a modally thin situational partner, falls short of knowledge, acquires an extrinsic disposition to knowledge (or, better said, an extrinsic disposition directed to the same dispositional partner as before, but that is manifested as knowledge) in virtue of a causal context that provides the disposition. Knowledge

${ }^{25}$ In the discussion that follows, I will remain neutral on the controversial issue of the metaphysical relation between dispositional and categorical properties. It is, however, important to notice that the standard view forcefully proposed by Prior, Pargetter, and Jackson (Prior, Pargetter \& Jackson 1982, 251-7), and, according to which, dispositional properties are grounded on prior categorical properties, has increasingly come under attack. It is rejected by pure dispositionalists such as Hugh Mellor (Mellor 1991, 104-22), who reduces the basic furniture of the universe to dispositional webs, by 'dualists' such as George Molnar (Molnar 2003, 14853), and by advocates of the 'surprising identity' theory and the Limit View, who consider the purely qualitative and the purely dispositional as the two sides of the same coin, that is, as the unrealizable limits (pure actuality and pure potentiality) of the same property (see Martin 2008, 54-79). For metaphysical reasons I would endorse the Limit View, as well as a twocategories ontology of substances and properties (where the latter are understood as modes of a substance). 
would thus be based on the agent's ability, but this ability would be made true by the safe environment that is partially responsible for conferring it to the agent. As a result, the safe environment becomes to all effects a causal power. The safety condition and the ability condition would thus be interlocked in such a way that mimics are avoided.

However, how could extrinsic dispositions be distinguished from cases of mimicking? There is, after all, an intuitive distinction between them, one that is made vivid by the contrast between the screwdriver that is extrinsically disposed to fit this particular screw head and a screwdriver that, lacking the proper shape and disposition, would have never unscrewed it but for the lucky intervention of a guardian angel. So, where does the difference lie? There is no possible doubt about the right answer: it is in the fact that, contrary to what happens with mimics, extrinsic dispositions rely on the intrinsic dispositions and intrinsic properties of their bearers. An account of the right relation between intrinsic and extrinsic dispositions thus is required to draw a principled distinction between cases of knowledge and cases of mimicking. The question for anti-luck virtue epistemologists that take this route is whether they have the appropriate means for that purpose.

At this point, one may be tempted to claim that the role played by intrinsic cognitive dispositions for the acquisition of knowledge would be that of being part of the causal basis for the extrinsic disposition to rightly obtain. The difference between mimics and extrinsic dispositions would thus lie in the fact that, only for the latter, intrinsic dispositions are causally operative for the result to obtain. The point would be that intrinsic cognitive dispositions are part of the sufficient causal conditions for the external disposition to obtain and be manifested as a high standing epistemic success when in the appropriate conditions, so that, were the agent bereft of the intrinsic epistemic ability that causally contributes to her extrinsic ability for getting knowledge, she would not succeed as a knower.

The problem for this view is that the inner disposition could easily be causally operative (even in a regular and systematic way) for the result to obtain, while compatible with mimicking.

Consider, for example, a perceptually competent agent that gains a disposition to know within a safe environment partially on the basis of her perceptual ability. The causal account would (at first sight rightly) classify this ability to know as an extrinsic disposition. However, had an intervening demon decided to cast a spell such that epistemic agents would hit the target of knowledge only if they are perceptually competent, the intrinsic disposition would be causally relevant for 
the outcome, while, owing to the fact that its causal contribution falls under the jurisdiction of the demon, this would be a standard mimic.

Doubtless some readers would indignantly protest against the previous argument. After all, and since it is at the very least misleading to describe a cognitive success due to the interfering demon as knowledge, it is the causal role played by the safe environment that explains the extrinsic ability and its right manifestation. However, the critic is missing the point of the argument. The question is whether causally operative intrinsic dispositions are the factor that differentiates extrinsic dispositions from mimics. And the answer is negative. Since causal contribution is compatible with mimicking, a causal relation between intrinsic and extrinsic dispositions is not the kind of relation that is right. The problem is that, deprived of such relation, the only way to capture the distinction at issue would be by appealing to the supposed difference between safe environments and mimics. This move is precluded by the arguments of the previous section, so that if there is something misleading in this discussion, it is to describe a cognitive success due to the causal powers of the safe environment as a case of knowledge.

There is, however, an alternative. It is possible to replace a causal relation by a grounding relation such that, contrary to what happens with mimics, the intrinsic disposition underlies the extrinsic disposition and is also manifested in the success of the latter.

This conception, that in my view provides the correct ontological picture of the relation between intrinsic and extrinsic dispositions, is made intuitive when considering the former as general dispositions directed to the same kind of partners, and the latter as dispositions relative to a particular partner that falls under the class specified by the directedness of the underwriting intrinsic disposition.

The thing is that the extrinsic disposition of this screwdriver to fit that screw head, a disposition that the former would lose without undergoing any change, is based on the screwdriver intrinsic disposition to fit screw heads slotted as this one is. This intrinsic disposition is retained as long as the shape and constitution of the tool are the same. It is required for the extrinsic disposition to be genuine. It is manifested in the success of the fitting. Crucially, it does have a content and directedness that, although general and indeterminate to a concrete individual, are constitutively included in the particularly determinate, broader, and highly externalized content of the extrinsic disposition. In short, extrinsic dispositions hold in virtue of the features of the causal context. This does not mean, however, that they are true only in virtue of that factor. On the contrary, they are also true in virtue of the intrinsic character of the innermost disposition on which are 
grounded. ${ }^{26}$ The point is thus that intrinsic dispositions, instead of being causally operative for the result to obtain, are manifested in that result as such. Mimics are by definition cases in which such manifestation does not occur.

Unfortunately for the advocates of extrinsic dispositions to knowledge, however, the grounding model is not applicable to their case. On their view, the intrinsic cognitive ability that underwrites the extrinsic ability is not-emphatically not-a general disposition directed to an infinite, but bounded, series of manifestations as knowledge under the right circumstances, one such that it would be retained by the agent even when there is a manifestation failure, and whose content and directedness are included in the directedness and content of the extrinsic disposition. Furthermore, on this model the intrinsic and the extrinsic dispositions are not simultaneously manifested in the same event under two different descriptions: as the screwdriver fitting this particular screw head, and as the screwdriver fitting a type of screw heads. The contents of the two dispositions do not match in the right way. Which curiously means that on this view there is not logical space for the relevant extrinsic cognitive dispositions at all. On reflection, this prima facie attractive route is logically precluded.

According to anti-luck virtue epistemologists knowledge is not explained by intrinsic dispositions. Extrinsic dispositions are likewise ruled out on account of their nature. Those categories being exhaustive, it seems as if a theory of this sort should be definitively rejected.

However, the next (and last) alternative for anti-luck virtue epistemologists is that of going internalist, but with a twist. In general metaphysics, nomic theories have been prevalent until recent times. ${ }^{27}$ There is no visible reason for not using them for epistemological purposes at a last resort.

At the core of this theory is the claim that the cognitive competences relevant for knowledge (those that, hypothetically, are paired to a modally thick safe environment) are partially intrinsic dispositions, to wit, that they are not only directed to the right environment for a mutual manifestation as knowledge in virtue of their intrinsic nature, but also in virtue of a fixed background of nomic necessities that function as nomic links, and that constitute nomological facts of

\footnotetext{
${ }^{26}$ This is just the point of Sosa's early account of the content of concepts (Sosa 1993, 3234). As usual, he was not only right on that particular issue, but opened the path for a broader application of his view to general metaphysics.

${ }^{27}$ The classical (and, plausibly, the most detailed) formulation of this view is the one proposed by Armstrong (1997, 220-62).
} 
the actual world. The point is thus that the epistemic dispositions relevant for knowledge are partly internal and partly external, or, in other words, that they can be lost under two different conditions: a change in the innermost competence of the agent, and a change of the laws that make that disposition appropriately operative. Importantly, those nomic necessities are metaphysically contingent, in the sense that in other possible worlds with different laws the same intrinsic disposition would yield different results (or no result at all). They are also extrinsic to the disposition, since they are not built into its contents. However, accidentality seems neatly avoided: once the law is kept fixed, there is no room for a lucky strike to occur.

It seems to me that the motivation for this final metamorphosis of anti-luck virtue epistemology would simply be dialectical: the avoidance of a robust virtue epistemology. However, it is worthwhile considering whether on further reflection this alternative is feasible.

To this end, consider the exact duplicate of an epistemic agent within a demon world. It would be plausible to claim that, owing to the interfering demon, the appropriate conditions for the manifestation of the agent's cognitive abilities are blocked, but that, crucially, her epistemic competences, however inhibited for manifestation, remain. On this intuitive view, the demon world is classified as a standard case of failure of manifestation.

Now consider how a nomic theorist would deal with the previous case. The demon world is such as not to be constituted by the nomological facts that constitute the actual world. ${ }^{28}$ The structural epistemic constitution, as well as the intrinsic nature of the relevant cognitive disposition, are the same for the agent within the actual world and for her counterpart. However, and since the extrinsic law that partially constitutes the epistemic competence does not hold in the demon world, the latter is deprived of her epistemic competence. It is not only that the competence fails to be manifested, but that the competence itself, and without the agent undergoing any intrinsic change, pops in and out of existence for no other reason than a change of location. There is an aura of irreality around this view.

However, the main problem concerns the role played on this theory by the intrinsic aspect of competences that, after all, are partially intrinsic. Do they have

\footnotetext{
${ }^{28}$ If the reader is not entirely satisfied by a demon world ruled by caprice, it is equally valid for the argument to replace it by a world constituted by a different set of nomological facts from those holding in the actual world.
} 
an intrinsic content and directedness to reciprocal manifestation with the right dispositional partners? An intrinsic for-ness towards fruitful togetherness? No, because such content is borrowed (from world to world, as it were) from the extrinsic law that connects the nature to the behaviour of the agent, and that it does so in such a way that a robust anti-realism about dispositions immediately follows. But this means that nature and intrinsic dispositional content dissolve into air, and that the intrinsic disposition is only effective as an occasional cause, that is, as a stimulus for the law to operate. With this we complete the circle by going back to a causal account of dispositions that, besides taking their dispositional character away, makes it impossible to distinguish competences from mimics. As a matter of fact, there is no ontological distinction between laws and universal and regular mimics. Which means that, when describing how epistemic abilities operate in the actual world, nomic theorists are really describing the world of a benevolent demon, one in which, while the acquisition of true beliefs is regular and systematic, the acquisition of knowledge is impossible. This is a world where inert epistemic agents are propelled by external forces, and where the constitution of the agent is only relevant, if at all, in the same way as dumbbells made of iron are relevant for a hovering fiend that casts a spell for all iron objects to be zapped when lightly touched. ${ }^{29}$

The conclusion is that the explanation of knowledge requires it to be grounded on real dispositions, where real dispositions are the building blocks underpinning the world and its regularities. As I said before, the first condition for making such explanation possible is by keeping the distinction between the conditions for the possession and the conditions for the manifestation of a disposition fixed.

\section{Higher-ORdER EPISTEMIC Dispositions}

Few contemporary epistemologists have been as aware of the Pyrrhonian problematic as Sosa is. ${ }^{30}$ On the one hand, Sosa's prolonged and careful dealing with this topic is a main factor to explain his view of the limited character and the

\footnotetext{
${ }^{29}$ For zapper-dependent dispositions, see Sosa $(2015,23)$.

${ }^{30}$ Descartes also was fully aware of this problematic, to the point of it being plausible to claim that he inherited from his Pyrrhonian predecessors a bi-level conception of the structure of knowledge, and that his epistemological project was mainly directed to make it possible a successful escape from the Agrippan net, and thus, to show that knowledge is after all possible. There is a direct line from Pyrrhonian epistemology through Descartes to Sosa.
} 
inadequacy of purely externalist accounts of knowledge, ${ }^{31}$ his endorsement of a bilevel epistemology, and his project of a healthy integration between the domain of animal functionings and the epistemic perspective proper of rational agents. On the other hand, Sosa's full appreciation of the Agrippan Trilemma has been instrumental for his defence of virtuous (and Cartesian) circularity, and for his rich and multi-level account of what it means for an agent to possess an epistemic perspective.

It is thus curious to notice how the other major strand of his epistemology - the competence account of knowledge-, one that is firmly connected to robust varieties of externalism, has come to effortlessly combine with the direction that epistemology has to take under the pressure of Pyrrhonian intuitions. The highorder competences of the rational agent are waiting at the end of both roads. And those competences, far from being the lurid floating debris and the epiphenomenal residuum of overdetermined first-order virtues, are instrumental to the constitution of knowledge and the reinforcement of the first-order abilities that underlie them. Barney's problem has proved to be the right opportunity that entwines rational integration as well as knowledge explanation to provide a fruitful coherence.

Sosa deals with this problem by considering two interrelated scenarios (Sosa 2015, 146-53) that involve a pilot in training (Simone), and that are respectively analogous to Barney's standard case, and to the case of Barney's counterpart within an environment that happens to be safe, but that it could easily be unsafe.

On the first scenario, Simone is shooting targets within a simulation cockpit that, unbeknownst to her, includes a screen such that sometimes is transparent (and Simone shoots at real targets) and sometimes reproduces holograms visually indiscernible from real targets. On the target-occasion she is successfully shooting real targets, and having a true belief about that event.

31 There is a parallel here with the Pyrrhonian critique of the pure externalism advanced by the Stoics, and with the Pyrrhonian insistence on claiming that it is not coherent (and thus, that it is not rational) for an epistemic agent to believe that $p$ while not believing whether she is justified in so believing (or while believing that she is not justified in so believing). [The transcendental argument that Sosa proposes at the end of Knowing Full Well hinges on the latter point. See Sosa $(2011,154-7)$.]

It seems, however, that the Pyrrhonians opposed some (but not all) varieties of Stoicism. After all, Cicero informs us that Zeno made a distinction between perceptual cognition and scientific knowledge. Something that seems confirmed by Strabo when describing the Stoics as claiming that scientific knowledge is a form of cognition such that it is "secure and unchangeable by reason" (Long \& Sedley 2014, 256 H1). This seems to support that at least some prominent members of the Stoa endorsed a bi-level epistemology. 
On the second scenario, Simone is carried blindfolded to a real cockpit in a real aircraft. She believes that at this stage of her training she always is piloting aircrafts. However, and unbeknownst to her, sometimes she is led to the simulation cockpit. On the target-occasion she is successfully shooting real targets aloft, and having a true belief about that event.

Unsurprisingly, Sosa considers that Simone lacks knowledge in the two cases even though she is forming true and apt beliefs on the basis of her faultless perceptual competence. However, and contrary to what happens with anti-luck virtue epistemologists, he does not provide an explanation of Simone's epistemic shortcomings in terms of the unsafety (or, as in the second scenario, of the weak safety) of Simone's surroundings. Sosa rather classifies those cases as instances of manifestation failure.

Manifestation failure of what? Granted that Simone is not just guessing, ${ }^{32}$ to wit, that she is not just affirming with the limited aim of getting her affirmation right (Sosa 2015, 75), but that she is affirming in the endeavour to affirm aptly, ${ }^{33}$ the answer is: a failure of her assessment of the epistemic situation such that, because she is not guided to the aptness of her beliefs by the aptness of that assessment, her beliefs are deprived of the full aptness that constitutes knowledge. The crux is thus that, while on the first scenario, and even though Simone forms a true second-order belief that were she to affirm that she is shooting real targets her affirmation will be true, her second-order belief that her affirmation would be apt (a second-order belief whose truth depends on the modally thick situation) is false, on the second scenario her second-order belief that her affirmation would be apt is, though true, inapt. In the latter case, her judgmental competence is not manifested in the success of her judgment due to how easily she might be badly situated. Proper rational guidance thus is the all-important factor that explains knowledge and the lack of it. Deprived of it, true, and even apt beliefs are, in one sense or another, merely accidental.

${ }^{32}$ Guessing is compatible with first-order aptness, as Sosa's example of the eye-exam (Sosa 2015, 74-81) makes perfectly clear. However, it automatically deprives a true and apt belief of the full aptness required for proper knowledge. Recall at this point the distinction made by the Stoics between a mere cognition and knowledge proper (see the previous footnote).

${ }^{33}$ This is how Sosa defines the act of judging, an act that goes well beyond the resultant seemings and the functional beliefs of first-order mechanisms, and that is proper of rational and volitional agents able to evaluate their first-order performances in view of a larger picture (of an epistemic perspective) that takes into account the reliability of first-order dispositions, and that includes an appreciation of the situation, and arguments pro and con that are properly pondered. Crucially, the agent's epistemic performances have to be guided to aptness by apt judging for achieving the status of knowledge. See Sosa $(2015,150-1)$. 
Importantly, the role played on this model by the modally thick situation is not that of a detached and additional factor. A strongly safe situation is just the right dispositional partner of the judgemental competence for mutual manifestation as fully apt belief. It is not that the environment has to be strongly safe period. Rather, it has to be strongly safe for its reciprocity to the second-order competence of the epistemic agent. This means that, though the background situational conditions for the manifestation of the competence are as operative as the latter for the result to obtain ${ }^{34}$, the right situations are included in the content and directedness of the second-order cognitive disposition as the conditions for its manifestation as knowledge. A metaphysical analysis of knowledge is thus provided, so that an ontological explanation of knowledge such that excludes Humean contingency is finally achieved.

Humean contingency may have well been avoided. However, the Pyrrhonian challenge as to why a complete competence that is not epistemically available to the experience of the performer (and that, in effect, is available to no one short of an omniscient God) is not a lucky success remains to be answered. The problem is not about the defeasible character of judgments, but about the fact that, even if all the assessments of the first-order abilities within a certain domain were infallible by virtue of the infallible nature of the target-competences, the agent would be deprived of access to what happens. From her perspective, a series of systematic and metaphysically grounded successes would be accidental.

But, what exactly is the challenge? As I read the Pyrrhonians, the challenge is not-emphatically not-about the nature of knowledge, as if the Pyrrhonians would be claiming that, because $S$ does not know that she knows that $p$, she does not know that $p$. To my mind, the Pyrrhonians are not committed to the controversial KK principle, a commitment that would prove to be the Achilles heel for their position. Plausibly, they would concede that the precedent picture is able to capture the nature of knowledge and to provide a right way of dealing with ontological accidentality. Their worries are about perspectival accidentality.

But then and again, what exactly is the challenge? It is about the proper rational attitudes to take for a rational agent. On the one hand, $S$ knows that $p$ because her judgment that $p$ is apt. On the other hand, $S$ 's judgment that, because her judgment

\footnotetext{
34 This is why, in a previous note, I expressed my reservations regarding an analysis of manifestation in terms of operative competences and background conditions. Both factors are equally operative. Which means that talk about background conditions always is relative to the interests of the theorist that wants to make salient a particular factor. There is nothing intrinsically wrong in such partial consideration. However, philosophical caution is highly recommended.
} 
that $p$ is apt, she knows that $p$, would never be apt. The Agrippan Trilemma is directed to make the agent aware of the last point. But with this awareness comes a full appreciation of the agent's cognitive disintegration. The point is that the agent would not be justified in claiming that her judgment is apt, so that she would be doomed to judge that $p$ while not believing that she is justified in so judging. There would thus be a discrepancy between the rational attitude (suspension of judgment) that she should take towards her judgment and her natural gravitation towards judgment. The agent would be, in this sense, blind to her knowledge: she would possess it, while prevented by the Pyrrhonian net to attribute knowledge to herself and to claim that she has knowledge. Absent silence, the agent would thus be charged with incoherence and irrationality.

Though the Pyrrhonian argument is perfectly valid regarding pure reliabilist accounts of knowledge, accounts which create an unbridgeable gap between rational justification and brute possession of knowledge, it is far from clear that it would be effective against Sosa' more sophisticated view. Sosa is too great a philosopher not to have defined the danger when he creates the safety. And the safety is, precisely, the judgmental competence.

The crux is that an agent that judges is not blind to her knowledge. What this means is not that the agent cannot go wrong, but that, even when mistaken, and because she is taking into account the relevant factors to rationally guide her belief to aptness (even if only implicitly), she is justified in so judging. Rational guidance being part of the explanation of why the agent has achieved knowledge, rational justification and knowledge possession do not come apart.

At this point the Pyrrhonian would insist that there is no possible gap to escape from the Agrippan Trilemma, and thus, that, the natural inclination to take for granted the reliability of our faculties being deprived of any epistemic status, there is a clash between the claims of reason and the force of nature. The main question is thus whether the Agrippa Trilemma deprives epistemic agents of rational justification, where 'rational justification' is justification enough to rightly claim that one knows.

Notice, firstly, that the Pyrrhonian argument (as constructed above) proceeds from the claim that, in virtue of the Agrippan Trilemma, the agent cannot aptly judge that she possesses knowledge, so that when ascribing knowledge to herself the agent always is, if right, accidentally so, to the conclusion that the agent is never justified to claim that she possesses knowledge. However, the entailment does not work. The question is not whether the agent can infallibly ascribe knowledge to herself, but whether she is justified in claiming knowledge. The point is that rational justification does not mean infallibility, so that the proper rational attitude 
to take for an agent could be that of affirming while fully aware of the defeasibility of such affirmation. If the Agrippan Trilemma only affects invulnerable claims of knowledge, then it cuts no ice for the issue at hand.

But, what about our basic and natural trust in the reliability of our cognitive competences? Is not the Agrippan Trilemma instrumental to make us aware of the irrationality of such attitude? The problem for the Pyrrhonians here is that there is no clear contrast between the claims of reason and the imperatives of nature. On the one hand, our competences are improved and refined through reason and experience, so that they are epistemically reinforced and gain epistemic status throughout the years. There is all the difference in the world between the blind trust of early childhood and the responsible consideration proper of rational and mature agents, even if the latter is built onto the former. On the other hand, the 'teachings of nature' are neither fleeting opinions nor blind instincts. It is plausible to claim, as Descartes did, that they come with the mark of the silent approval of reason. All in all, the Pyrrhonian arguments seem only able to deprive certain natural commitments of metaphysical certainty. However, they do not make them improbable enough as to create equipollence and to support suspension. Discrepancy is thus replaced by integration. ${ }^{35}$

The conclusion is that Sosa's complex and consistent view is not only able to successfully provide an ontological analysis of knowledge, but to do it in such a way that it also breaks the Pyrrhonian impasse. It is important, however, to consolidate and to explore, if only because of the huge consequences for epistemology of taking such revolutionary step towards metaphysical analysis, a step that implies that conceptual analysis alone cuts no ontological ice.

35 As a matter of fact, the Pyrrhonian challenge might be met in a straight way, either by arguing that, because it makes no sense to talk about the rational attitude for the agent to take without endorsing the general reliability of our cognitive competences, the Pyrrhonians cannot coherently contrast the claims of reason with the force of nature (this is the procedure used by Sosa in his transcendental argument), or by taking up the project of self-validating reason, an internal project that makes good use of the deliverances of reason to reduce radical scepticism to absurdity (this is the Cartesian procedure to deal with the Pyrrhonian challenge). Importantly, both projects proceed by virtuous circularity. It is also significant to note that their function is not that of providing justification to the agent's claim of knowledge, as if one were unjustified before engaging in technical and demanding arguments, but that of providing a conviction so firm that, unchangeable by reason, could beat the sceptic even in his own terrain. Thus, there are cases in which the agent would have a knowing grasp of the fact that she knows. In those cases, the possession of knowledge is fully available to the epistemic subject. 
For one thing, competences and powers being multi-track, blockers, mimics and inhibitors are perspectival in the sense of being relative to the interests of the describer and of the epistemic community. There is thus room within metaphysical analysis for a social epistemology, so that one can coherently endorse a robust realism regarding the bases of our taxonomies while according to them a contextual and relativized function.

It is also relevant to notice that manifestation is an internal relation, one such that the outcome is simultaneous with the reciprocity of its dispositional bases. It is not only that internal relations are beyond the grasp of traditional (Humean) conceptions of causality, but that they could plausibly shed new light on causality itself. It would be worthwhile exploring whether and to what extent (external) causal relations could be reduced to (internal) relations of reciprocal manifestation.

But the problem that, at least to my mind, seems more pressing is that of elucidating the ontological status of epistemic manifestations, so that the troubled waters between ontological anti-realism and ontological inflation may be navigated. One way to put this problem is to say that the contrast between cognitive dispositions and their manifestations suggests a further contrast between the manifest and the ontological image of knowledge. The same point could be put by saying that, truths about knowledge being relational truths, it is relevant to determine whether their truthmakers are non-relational features of the world. If this were the right answer, there would be room within a virtue epistemology for a view that combines a robust realism regarding the truth of knowledge ascriptions with an unequivocal rejection (because ontological features would be that which make them true) of supervenient levels of reality. On this view, the conceptual and the ontological discourses would be mutually irreducible ways of representing the same world.

The fact remains: Sosa has broken the hold of Humean contingency in epistemology. This places his true stature as a philosopher in proper perspective. ${ }^{36}$

Modesto Gómer-Alonso UPS A/University of Edinburgh mgomezal@upsa.es

\footnotetext{
${ }^{36}$ This article has been funded by the Research Project "Points of View, Dispositions, and Time. Perspectives in a World of Dispositions" (FFI2014-57409-R. Gobierno de España. Ministerio de Economía y Competitividad. Programa Estatal de Investigación, Desarrollo e Innovación).
} 


\section{BIBLIOGRAFÍA}

Armstrong, D.M. (1997), A World of States of Affairs, Cambridge: Cambridge University Press.

- (1983), What is a Law of Nature?, Cambridge: Cambridge University Press.

BetT, R. (ed.) (2005), Sextus Empiricus. Against the Logicians, Cambridge: Cambridge University Press.

Bonjour, L., SOSA, E. (2003), Epistemic Justification. Internalism vs. Externalism, Foundations vs. Virtues, Oxford: Blackwell.

HeIL, J. (2012), The Universe As We Find It, Oxford: Clarendon Press.

HeIl, J., Mele, A.R. (eds.) (1993), Mental Causation, Oxford: Oxford University Press.

LeHrer, K., Cohen, S. (1983), "Justification, Truth, and Coherence", Synthese 55 (2), 191-207.

Long, A.A., SEDley, D.N. (2014), The Hellenistic Philosophers. Volume 1, Cambridge: Cambridge University Press.

Martin, C.B. (2008), The Mind in Nature, Oxford: Clarendon Press.

- (1994), "Dispositions and Conditionals", The Philosophical Quarterly 44, 1-8.

Mellor, H. (1991), Matters of Metaphysics, Cambridge: Cambridge University Press.

Molnar, G. (2003), Powers. A Study in Metaphysics, Oxford: Oxford University Press.

Prior, E., PARgetTer, R., Jackson, F. (1982), "Three Theses About Dispositions", American Philosophical Quarterly 19, 251-57.

PritChARD, D. (2012), "Anti-Luck Virtue Epistemology", The Journal of Philosophy 109 (3), 247-79.

- (2009): Knowledge, Basingstoke: Palgrave Macmillan.

Pritchard, D., Millar, A., Haddock, A. (2010): The Nature and Value of Knowledge. Three Investigations, Oxford: Oxford University Press.

SCHAFFER, J. (2010), “The Debasing Demon”, Analysis 70 (2), 228-37.

SosA, E. (2015), Judgment and Agency, Oxford: Oxford University Press.

- (2011), Knowing Full Well, Princeton \& Oxford: Princeton University Press [Trad. esp.

de Modesto Gómez-Alonso, Con pleno conocimiento, PUZ, 2014].

- (2009), Reflective Knowledge. Apt Belief and Reflective Knowledge, Volume II, Oxford:

Clarendon Press.

- (1997), "How to Resolve the Pyrrhonian Problematic: A Lesson from Descartes",

Philosophical Studies 85, 229-49.

- (1993), "Abilities, Concepts, and Externalism", in J. Heil \& A.R. Mele (eds.), Mental Causation. Oxford: Oxford University Press, 309-29. 